\title{
OS “DETETIVES” DOS ROMANCES POLICIAIS MÍSTICO-RELIGIOSOS
}

\section{THE "DETECTIVES" OF MYSTIC- RELIGIOUS POLICE NOVELS}

FERNANDA MASSI *

RESUMO: Tendo em vista que o detetive é o personagem mais importante da narrativa policial, este trabalho analisa, sob o viés da semiótica discursiva, a caracterização do perfil dos sujeitos que realizam as investigações nos chamados "romances policiais místico-religiosos" mais vendidos no Brasil de 1980 a 2009. Nessas narrativas, além de encontrar o sujeito que realizou o crime e entregá-lo a um destinador-julgador, responsável por sua punição, o "detetive" deve proteger um segredo místico-religioso pertencente a uma sociedade fechada. Além de não serem sujeitos extraordinários (como Auguste Dupin, Sherlock Holmes, Hercule Poirot etc.), os "detetives" dos romances policiais místico-religiosos nem sempre conseguem ser eficazes no cumprimento de suas tarefas.

PALAVRAS-CHAVE: Romance policial. Detetive. Segredo. Misticismo. Religiosidade.

ABSTRACT: Considering that the detective is the most important character of police narrative, this work analyzes, under the bias of discursive semiotics, the characterization of

* Pesquisadora da UNESP - Universidade Estadual Paulista. E-mail: massi@fclar.unesp.br. 
the profile of the subjects carrying out investigations in socalled "mystical-religious police novels" most sold in Brazil from 1980 to 2009. In these narratives, in addition to finding the subject who performed the crime and delivering it to a sender-judge responsible for his punishment, the "detective" must protect a mystical-religious secret belonging to a closed society. Besides not being extraordinary subjects (such as Auguste Dupin, Sherlock Holmes, Hercule Poirot etc.), the "detectives" of the mystical-religious police novels cannot always be effective in fulfilling their tasks.

KEYWORDS: Police novel. Detective. Secret. Mysticism. Religiosity.

\section{Introdução}

Sob o viés da semiótica discursiva de origem greimasiana, analisamos os romances policiais mais vendidos no Brasil de 1980 a 2009. Dentre os livros selecionados, destacamos aqueles que constituíam um subgênero da narrativa policial, que chamamos de "romance policial místico-religioso" (MASSI, 2013). São eles: O nome da rosa, de Umberto Eco (ECO, 2010); O último cabalista de Lisboa, de Richard Zimler (ZIMLER, 2007); Os crimes do mosaico, de Giulio Leoni (LEONI, 2006); O último templário, de Raymond Khoury (KHOURY, 2006); O código da Vinci (BROWN, 2004a), Anjos e demônios (BROWN, 2004b) e O símbolo perdido (BROWN, 2009), de Dan Brown.

Nestas narrativas, o cerne da investigação realizada pelo “detetive" não é, apenas, a busca da identidade do criminoso. De um lado, há um segredo místico-religioso protegido por uma sociedade fechada que deve ser mantido. De outro, há 
um sujeito ou uma sociedade inimiga querendo revelar tal segredo para a sociedade aberta. A trama se organiza em torno da disputa pela revelação ou manutenção desse segredo e muitas mortes ocorrem até que um dos lados saia vencedor. Apenas nos romances policiais místico-religiosos $O$ nome da Rosa e Anjos e demônios, em que o criminoso age em defesa de uma sociedade fechada, o sujeito que realiza a investigação não está encarregado de impedir a revelação do segredo, já que essa é a função do criminoso. Nos outros cinco romances policiais místico-religiosos, porém, um sujeito é manipulado a realizar a investigação para impedir que o assassino descubra e revele o segredo pertencente a uma sociedade fechada.

Tendo em vista que o detetive é a personagem central da narrativa policial, já que determinou a criação desse tipo de texto, discutiremos, neste artigo, a caracterização do perfil dos sujeitos que realizam a investigação nos romances policiais místico-religiosos. Curiosamente, tais sujeitos não recebem o título de "detetive" em nenhum dos sete romances policiais místico-religiosos estudados, mas também não são nomeados de nenhuma outra forma (por exemplo, investigadores, policiais etc.). Nossa escolha pelo estudo desse sujeito do fazer deveu-se às modificações que ele sofreu no romance policial místico-religioso. Inicialmente, descreveremos o perfil dos detetives do romance policial clássico - tais como Auguste Dupin (de Edgar Allan Poe), Sherlock Holmes (de Conan Doyle) e Hercule Poirot (de Agatha Christie) - para, posteriormente, fazer uma comparação entre esses sujeitos e os "detetives" do romance policial místico-religioso.

\section{0 detetive e o romance policial}

Com o surgimento do detetive Auguste Dupin nos con- 
tos de mistério de Edgar Allan Poe (POE, 2010), publicados no século XIX, "Os crimes, então, passam a ser investigados e solucionados por uma personagem específica, criada mesmo para esse fim, e não por personagens sobrenaturais ou que entraram na trama por acaso [...]" (MARTINS, 2005, p. 172173). Dessa forma, o detetive se consagrou como a personagem mais importante da narrativa policial, devendo realizar sua investigação de forma eficaz, para que sua presença no enredo faça sentido.

Ainda no século XIX, surgiram detetives sucessores de Auguste Dupin, tais como Sherlock Holmes, criação de Arthur Conan Doyle.

Esses detetives do século XIX carregam na sua constituição de sujeito a crença de que as ciências poderiam ser a resposta para entender não apenas o homem, como também a estrutura de sua organização social. Os métodos utilizados pelos estudos científicos, acreditava-se, poderiam contribuir para todas as áreas do conhecimento, bastando, para isso, que fosse percebido o fenômeno e, ao mesmo tempo, determinadas as leis que o regiam, segundo a concepção positivista, que vigorava na época. Além disso, o desenvolvimento, a proliferação e o escalonamento social dos centros urbanos e, acrescenta-se, o advento da imprensa, foram condições necessárias para que o gênero policial, via Poe e Doyle, conquistasse o gosto do público (MARTINS, 2005, p. 175-176, grifo do autor).

Nos romances policiais tradicionais, o sujeito que realizava a investigação em busca da identidade do criminoso era nomeado detetive porque trabalhava como profissional liberal, sendo remunerado pela investigação realizada; tinha experiência, reconhecida pela sociedade e pela polícia, na busca de criminosos; não tinha qualquer envolvimento ou relação 
afetiva, parental ou profissional com as vítimas - que ele não conhecia - ou com as famílias delas; era um sujeito inteligente, perspicaz, frio e calculista, dotado de um raciocínio lógico e matemático e, enfim, não aceitava ou pedia ajuda a outras pessoas, pois sabia que era capaz de encontrar o criminoso sozinho.

Embora muitos leitores se lembrem de "meu caro Watson" ajudando Sherlock Holmes na investigação, esse tipo de sujeito não compartilha do mesmo método que o detetive nem conhece as informações relevantes para a conclusão da investigação, descobertas pelo detetive propriamente dito. Watson era o narrador das histórias de Conan Doyle e sua falta de habilidade para lidar com as informações e as pistas que levavam ao criminoso ressaltava, ainda mais, a inteligência de Sherlock Holmes, que conseguia resolver o enigma a partir dos mesmos indícios. Martins (2000) define sujeitos desse tipo como "pseudodetetives", pois "querem resolver o crime, [...] buscam informações a respeito dele e acompanham a investigação de perto. No entanto, não conseguem estabelecer uma relação entre vítima, crime e criminoso" (MARTINS, 2000, p. 90). Embora detenham as informações necessárias à solução do crime, eles não são capazes de organizá-las. Isso ocorre por falta de interesse, de conhecimento ou devido à idolatria que mantêm em relação ao detetive que acompanham. Para Albuquerque (1973, p. 87),

A solução do mistério é alcançada pelo detetive, muitas vezes, através de uma observação fortuita de seu auxiliar; o leitor inteligente e observador poderá também chegar ao mesmo resultado. No entanto, o auxiliar apresentará sempre uma verdadeira obstrução cerebral, só entendendo o fato depois dele [sic] ser exaustivamente explicado pelo herói. 
Há também, segundo Martins (2000, p. 85), os "auxiliares do saber", representados por vizinhos, empregados, testemunhas oculares, anônimos etc.

São aqueles que levantam hipóteses ou fazem acusações ou julgamentos a partir de interpretações bastante subjetivas. Eles são auxiliares segundo o saber, ou seja, exercem o papel de possuir um saber a ser compartilhado, pois informam sempre algo novo àquele que efetivamente investiga o crime, o detetive. Esse saber pode ser, se não a chave do enigma, um elemento orientador fundamental para o decorrer das investigações: a situação do crime, suas circunstâncias, o passado da vítima, etc. (MARTINS, 2000, p. 85).

Os auxiliares do saber não estão encarregados de realizar a investigação, porém, quando percebem que podem auxiliar o "detetive" ou incriminar um inimigo, não hesitam em apresentar suas reflexões, ideias, hipóteses, seus comentários, motivados pelo dever auxiliar o detetive e pelo querer estar conjunto com a verdade. Cabe ao detetive julgar a importância desses depoimentos e a relação desses sujeitos com os acusados, a fim de não comprometer a veracidade do resultado.

No romance policial tradicional o detetive era um delegado da sociedade: lutava por seus valores e ideais e, ao ser escolhido para realizar a investigação, estabelecia um contrato fiduciário com seu destinador-manipulador, representado pela polícia (que ainda não tinha encontrado a solução do mistério) ou por um sujeito relacionado à vítima. Nesse contrato, o detetive se comprometia a encontrar a identidade do assassino e entregá-lo a um destinador-julgador para que fosse devidamente punido. A sociedade, por sua vez, na qual se incluía(m) a(s) vítima(s) e o próprio criminoso, aguardava ansiosamente a resolução do crime e a punição do assassino 
para que a paz e a ordem fossem restabelecidas e a justiça fosse feita.

Esse tipo de texto determina a seguinte programação: um sujeito realiza um crime e mantém sua identidade em segredo; o detetive é acionado para encontrá-lo e entregá-lo a um destinador-julgador, que será responsável por sua punição. A performance do detetive é, portanto, uma sanção negativa no percurso do criminoso. 0 observador ou sancionador que julgará a eficácia da performance do detetive pode ser tanto o destinador-manipulador de seu fazer, no enredo, quanto o leitor, que aguarda pela resolução do enigma e confia na atuação do detetive.

Os detetives dos romances policiais tradicionais determinam as regras da investigação a partir de um raciocínio lógico, um método a ser seguido, o qual, de preferência, já tenha se mostrado eficaz em outras investigações. A ação do detetive deve visar a um resultado rápido e preciso sem que, no entanto, desrespeite as regras do gênero policial e parta para o inverossímil, ou seja, o criminoso deve ser encontrado pela lógica e não por confissão, mágica, sessão espírita ou derivados. Quando o detetive tem experiência, o esquema de organização das informações já está determinado em sua mente e ele pode utilizar os mesmos princípios para descobrir o culpado pelo crime.

Como o detetive era o único sujeito capaz de encontrar a resolução do mistério em torno de um ou mais assassinatos, estava imune a qualquer tipo de violência, mesmo aquela cometida pelo assassino. Embora o criminoso sempre soubesse quem era o sujeito responsável pela investigação, não se atrevia a se aproximar dele, temendo que sua identidade fosse descoberta. Portanto, no romance policial tradicional, o único sujeito que amedronta o criminoso é o detetive, que 
não perdoaria seus atos aplicando-lhe uma sanção negativa, representada, por exemplo, pela entrega do culpado à polícia e sua consequente prisão.

\section{0 "detetive" do romance policial místico- religioso}

Nos romances policiais místico-religiosos estudados neste trabalho, o perfil do "detetive" e sua área de atuação foram modificados. Os atores que desempenham a função de detetive não são profissionais, ou seja, não trabalham como detetives liberais, não realizam a investigação sozinhos e não estão buscando apenas a identidade de um assassino, mas também um segredo místico-religioso que pode ter causado a morte de algumas pessoas. Na maioria das vezes, esse sujeito se envolve com a investigação porque mantém uma relação afetiva, parental ou profissional com a vítima. Uma vez que o sujeito que realiza a investigação não é mais um delegado da sociedade, ele não estabelece um contrato fiduciário com ela. Sendo assim, a única pessoa que aguarda a resolução do crime é o destinador-manipulador do fazer investigativo, que muitas vezes é o próprio sujeito do fazer - o que elimina de vez o estabelecimento de um contrato fiduciário entre o detetive e a sociedade. Isso significa que a solução do mistério resolvido por esse sujeito interessa apenas ao leitor, que sabe quem está realizando a investigação.

Em alguns romances policiais místico-religiosos, a investigação tem início para que se cumpra um contrato fiduciário previamente estabelecido com a vítima, que foi assassinada por ter se recusado a romper tal contrato, no qual se comprometia a manter um segredo. Isso ocorre, por exemplo, em $O$ código Da Vinci, em que Jacques Saunière foi assassinado por ter se recusado a revelar o segredo protegido pelo Priorado de Sião, do qual ele era um dos guardiões. 
A ausência de um contrato fiduciário ou a restrição de sujeitos envolvidos nesse contrato diminui a responsabilidade daquele que realiza a investigação para encontrar o criminoso e entregá-lo a um destinador-julgador. Como a investigação está relacionada a um segredo místico-religioso, cabe a esse sujeito se ocupar, principalmente, da resolução do enigma. A identidade do criminoso acaba sendo descoberta como consequência de outra investigação, já que a motivação do assassino sempre se relaciona ao segredo. Mais importante do que punir o criminoso, portanto, é impedir a revelação do segredo descoberto, que pertence a uma sociedade fechada.

Os contratos fiduciários estabelecidos entre os personagens aparecem em grande quantidade nos romances policiais místico-religiosos estudados. Tais contratos nem sempre estão ligados às relações entre o destinador-manipulador e o suposto detetive ou entre o sujeito que realiza a investigação e a sociedade, mas sempre resultam em mortes, seja para garantir o cumprimento ou por conta da ruptura desses contratos, muitos dos quais foram estabelecidos entre a vítima e o sujeito que realiza a investigação. Em $O$ último cabalista de Lisboa, por exemplo, Berequias Zarco havia se comprometido com seu tio, que fora assassinado, a não revelar o segredo sobre o grupo cabalístico que ele comandava. Dessa forma, um sujeito é levado a querer encontrar o culpado pelo crime a fim de manter o segredo que determinou a instauração do contrato fiduciário, temendo que o criminoso revele a verdade.

Nesse contexto, há um tipo de contrato fiduciário estranho ao gênero policial que se manifesta nos romances policiais místico-religiosos $O$ nome da Rosa e Os crimes do mosaico. É aquele estabelecido entre o sujeito que realiza a investigação e o criminoso, após a descoberta de sua identidade. Em $O$ nome da Rosa, tal contrato ficou implícito a partir do momento em que o criminoso provocou um incêndio com o objetivo de matar o 
sujeito que havia realizado a investigação e seu auxiliar. Além disso, o assassino eliminou todas as provas que confirmavam a verdade, impedindo o sujeito que realizou a investigação de revelá-la. Em Os crimes do mosaico, tal contrato foi proposto pelo criminoso em troca do objeto-valor que teria sido o motivo para os assassinatos - os mapas que indicavam o caminho para uma nova Babilônia. Dessa forma, o enunciador de Os crimes do mosaico constrói a imagem de um sujeito corruptível que era o prior da cidade e, portanto, tinha a obrigação de encontrar e punir o criminoso, mas preferiu receber uma recompensa por sua investigação a cumprir seu dever. Entretanto, após o estabelecimento desse contrato fiduciário, o navio do criminoso foi acometido por um incêndio de causas desconhecidas e o detetive queimou os mapas que havia ganhado por ter se arrependido da negociação. Nesses dois romances policiais místico-religiosos, o contrato fiduciário estabelecido após a conclusão da investigação - entre o sujeito que a realizou e o criminoso - foi cumprido.

Caso semelhante ocorreu no romance policial tradicional Assassinato no Expresso Oriente, de Agatha Christie, mas a causa da instauração do contrato fiduciário foi bastante diferente. O detetive Hercule Poirot viajava a trabalho quando foi surpreendido pelo assassinato de um sujeito dentro do trem Expresso Oriente. Após concluir a investigação, Poirot descobriu que os doze passageiros do trem haviam apunhalado a vítima e, portanto, eram culpados pelo crime. A motivação de tal ato, porém, era o sequestro de uma criança e o assassinato de seus pais, crime cometido pela vítima do trem, ou seja, tratava-se de uma punição ao criminoso, uma vingança organizada por familiares e amigos da família exterminada. Diante das causas do crime, Hercule Poirot e o diretor da empresa de trens, que viajava no mesmo vagão, decidiram acobertar os criminosos e atribuir a culpa a um suposto sujeito que teria invadido o trem quando a neve interrompeu a viagem. 
Nos dois romances policiais místico-religiosos comparados à obra de Agatha Christie, O nome da Rosa e Os crimes do mosaico, os assassinatos não são cometidos por vingança, mas sim para proteger um segredo. Nesse subgênero da narrativa policial, o criminoso é mais forte e mais corajoso e, na maioria das vezes, ataca o sujeito da investigação de modo violento. Em Os crimes do mosaico, por exemplo, o criminoso Veniero Marin travou uma luta corporal com o responsável pela investigação, Dante Alighieri, ameaçando-o com um punhal. Em $O$ símbolo perdido, o criminoso Zachary Solomon convocou Robert Langdon para que ele o ajudasse a desvendar os segredos da pirâmide maçônica, mas tentou matá-lo afogado em uma piscina. Os sujeitos que realizam a investigação, portanto, sofrem todo tipo de violência - ameaças, agressões físicas, perseguições, sequestros -, mas não são assassinados. Entretanto, essa disputa entre o sujeito que realiza a investigação e o autor dos crimes é, às vezes, tão acirrada que o criminoso acaba sendo morto pelo responsável pela investigação, como ocorre em $O$ último cabalista de Lisboa.

Outra característica dos romances policiais místico-religiosos é a existência de duas investigações: uma em busca da identidade do criminoso, com o objetivo de que ele seja encontrado e punido; outra em busca do segredo místico ou religioso relacionado ao assassinato. Algumas vezes, essas duas investigações são realizadas ao mesmo tempo e pelos mesmos sujeitos, numa relação de causa e consequência. Ou seja, o criminoso sempre tem alguma relação com o segredo e descobrir sua identidade facilita o caminho a ser percorrido por aquele que realiza a investigação. Em outras narrativas, a polícia busca a identidade do criminoso, para que ele seja punido pelos assassinatos, e os sujeitos envolvidos com a vítima realizam a outra investigação, pois querem entender os motivos do crime e proteger o segredo místico-religioso.

Com exceção de Os crimes do mosaico, os sujeitos que re- 
alizam a investigação nos romances policiais místico-religiosos estudados contam com a ajuda de um ou mais aliados, que também pode $(\mathrm{m})$ contribuir para a decifração de códigos e mistérios envolvendo o assassinato, ao compartilharem suas descobertas. Não há hierarquia no trabalho desses sujeitos e nenhum deles é mais perspicaz do que o outro, já que as informações coletadas se complementam. Como os crimes são sempre realizados em função de questões místico-religiosas, pelo menos um dos sujeitos que realiza as investigações pertence a uma dessas áreas. A investigação, portanto, não é caracterizada como um inquérito policial e não exige a presença de especialistas da área criminal. O que ocorre, muitas vezes, é a descoberta da identidade do criminoso como consequência dessa investigação sobre o segredo místico-religioso.

O envolvimento afetivo de alguns dos sujeitos que realizam a investigação com as vítimas também é novidade no gênero policial, já que o detetive raramente as conhecia no romance policial tradicional. As paixões da vingança e da justiça contribuem para que os sujeitos que realizam a investigação, nos romances policiais místico-religiosos, sejam bem-sucedidos em suas apurações. Berequias Zarco, por exemplo, personagem de $O$ último cabalista de Lisboa, havia perdido seu referencial de homem com a morte do tio e desejava, de forma intensa, encontrar e punir o assassino, agindo pela paixão da vingança.

\section{A eficácia dos "detetives" dos romances policiais místico-religiosos}

O conceito de "eficácia", de acordo com a semiótica discursiva, é uma grandeza orientada que exige um ponto de vista e pressupõe um observador ou sancionador, que a julgará. 
Tal grandeza faz parte do esquema narrativo canônico, que - de acordo com o percurso gerativo do sentido - compreende as etapas da manipulação, competência, performance e sanção dos sujeitos do fazer. Dessa forma, a eficácia implica um contrato fiduciário estabelecido entre destinador e destinatário, no qual há regras operatórias a serem seguidas pelo sujeito do fazer.

A eficácia pode ser aplicada ao percurso narrativo realizado pelo sujeito do fazer investigativo no romance policial. Nesta seção, analisaremos a eficácia da performance investigativa nos romances policiais místico-religiosos estudados para verificar se os sujeitos que a realizaram obtiveram ou não bons resultados, de acordo com a programação que deveriam seguir: encontrar a identidade do criminoso e impedir que ele revelasse o segredo místico-religioso protegido por uma sociedade fechada.

Nos romances policiais místico-religiosos, geralmente, o sujeito que realiza a investigação é seu próprio destinador-manipulador e o destinador-julgador de seu fazer é o leitor, que aguarda ansiosamente pela resolução dos enigmas. Quando os programas narrativos são executados de maneira eficaz pelo "detetive", a sanção realizada pelo destinador-julgador é positiva, ou seja, o leitor é recompensado pela revelação da identidade do criminoso.

Greimas e Courtés definiram "eficácia" no Dicionário de Semiótica (GREIMAS; COURTÉS, 2008, p. 156, grifo do autor) da seguinte maneira:

\section{EFICÁCIA s.f.}

FR. EFFICACITÉ; INGL. EFFICACITY

1. Em seu emprego corrente, eficácia é a capacidade de produzir um máximo de resultados com um mínimo de esforço 
(Petit Robert). Uma teoria semiótica, e os modelos que ela permite construir, são ditos eficazes quando, obedecendo aos princípios de simplicidade e de economia, são ao mesmo tempo projetivos, pelo que possibilitam prever e explicar grande número de fatos.

2. Falando-se de uma teoria formalizada, diz-se que ela é eficaz quando as regras que formula são operatórias, isto é, suscetíveis de serem executadas por um autômato. Sabe-se que o conceito de eficácia substitui, ao menos em parte, nas linguagens formais, os critérios de verdade.

$\rightarrow$ Operatório

A primeira acepção de "eficácia", definida pelo dicionário Petit Robert, trata de uma definição corrente do termo, adotada pelo senso comum. Já na segunda acepção, nota-se a relação entre os termos "eficácia" e "operacionalidade", ou seja, a eficácia pressupõe regras operatórias para que possa existir. Isso significa que um percurso narrativo só é eficaz quando o sujeito do fazer determina, previamente, os passos para execução de sua performance, demonstrando a competência necessária para realizá-la, e consegue cumprir aquilo a que se propôs, sendo sancionado positivamente por um destinador-julgador.

Também é importante destacar a afirmação de que o termo "eficácia" substitui os critérios de verdade - discutidos em Du Sens II, quando Greimas (1983) explica a relação entre verdade e eficácia ao tratar da manipulação discursiva. A verdade, para a teoria semiótica, é um efeito de sentido, ou seja, é uma construção do discurso embasada em um "fazer-parecer-verdadeiro". 0 "parecer" não é apenas uma adequação do discurso ao enunciado, mas sim a adesão do destinatário ao qual o enunciador se dirige, que é condicionada pela enunciação. 0 destinatário, por sua vez, é o único capaz de sancionar o contrato de veridicção. Podemos entender, portanto, 
que a eficácia da investigação se dá quando os sujeitos que a realizaram conseguem impor a verdade (o "fazer-parecerverdadeiro") ao leitor, mostrando o modo como desvendaram os enigmas em torno do crime.

A eficácia de uma performance só se realiza se houver uma programação, um conjunto de regras a serem seguidas por um sujeito do fazer. Essas regras precisam ser planejadas com clareza e bem definidas para que possam ser executadas com precisão. A partir dessas definições do conceito de "eficácia” para a semiótica discursiva, vejamos se os sujeitos que realizam as investigações nos romances policiais místico-religiosos estudados executam performances eficazes.

Em $O$ nome da Rosa, o abade Abbone acreditava que Guilherme William de Baskerville era o único sujeito capaz de encontrar o culpado pelos misteriosos assassinatos que vinham ocorrendo no mosteiro. Ao contrário do que os monges pensavam, Guilherme não acreditava que forças diabólicas fossem a causa do crime e optou por seguir um raciocínio lógico em busca de provas concretas que indicassem o culpado. Diante disso, Abbone pediu a ele que tivesse cautela para não comprometer a reputação do mosteiro. Adso de Melk era discípulo e escrivão de Guilherme e o acompanhava na investigação, porém, além de ser bastante jovem e saber muito pouco sobre religião, não conseguia controlar seu medo do assassino, o que o impedia de raciocinar a partir dos indícios encontrados. Segundo as discussões de Martins (2000), Adso pode ser considerado um "pseudodetetive". 0 encantamento de Adso diante da perspicácia de seu mestre na resolução dos enigmas tem a função de valorizar a inteligência de Guilherme e, com isso, passar ao leitor uma imagem verdadeira de sua competência.

Considerando-se a necessidade de se estabelecer uma 
programação antes do início da investigação, pode-se dizer que Guilherme de Baskerville foi eficaz na realização de sua performance, pois conseguiu realizá-la em pouco tempo e obteve bons resultados. De todos os sujeitos que realizam as investigações nos romances policiais místico-religiosos, Guilherme de Baskerville é o que mais se aproxima do perfil dos detetives dos romances policiais tradicionais, pois utiliza um método próprio de investigação, semelhante ao de Sherlock Holmes, que tinha uma capacidade apurada de dedução a partir de pequenos indícios. Seu nome - que representa sua origem, de Baskerville - faz referência ao livro 0 cão dos Baskerville, de Arthur Conan Doyle. Por sua vez, o discípulo Adso de Melk tem função semelhante à do Dr. Watson, companheiro de Holmes, pois também é o narrador da história e detém inúmeras informações sobre o crime, embora não consiga organizá-las. Além disso, o diálogo respeitoso entre Guilherme de Baskerville e Jorge de Burgos, na cena em que a identidade criminosa do bibliotecário é descoberta, assemelha-se aos diálogos entre Sherlock Holmes e o Professor Moriarty, maior inimigo do detetive e considerado, por Holmes, um "gênio do crime".

Em $O$ último cabalista de Lisboa, o sujeito que realizou a investigação, Berequias Zarco, procurava o assassino de seu tio, o mestre cabalista Abraão Zarco. Embora trabalhasse com o tio na confecção de iluminuras judaicas, Berequias teve dificuldades com a investigação, pois não conhecia todos os segredos protegidos pelos judeus e pela cabala. Além disso, quando Abraão foi assassinado, iniciou-se na cidade um ataque dos cristãos aos judeus, levando à morte muitas pessoas que poderiam ajudá-lo na investigação. Ao mesmo tempo em que buscava o assassino de seu tio, Berequias, como único homem da casa, tinha a necessidade proteger sua família dos cristãos-velhos e encontrar o irmão caçula, que estava desa- 
parecido havia alguns dias. Essa característica de desempenhar várias funções ao mesmo tempo não era comum entre os detetives clássicos, que deveriam se ocupar única e exclusivamente da investigação em busca do criminoso.

Durante a investigação, Berequias contou com a ajuda de um grande amigo de infância, Farid, que também era judeu e, pelo fato de não sofrer tanto com a morte de Abraão, ajudava a raciocinar de forma lógica em busca do culpado. Nesse romance policial místico-religioso, tem-se um exemplo perfeito de trabalho em dupla, já que cada um dos integrantes, com suas limitações e qualificações, precisava e colaborava com o outro. Além disso, a performance investigativa foi eficaz, pois, mesmo sem ter experiência em investigações criminosas, Berequias Zarco conseguiu estabelecer um plano de ação para encontrar o assassino em pouco tempo e de forma precisa.

Assim como no romance policial $O$ último cabalista de Lisboa, em $O$ código Da Vinci também há um caso de parentesco entre a vítima, Jacques Saunière, e um dos sujeitos que realiza a investigação, sua neta Sophie Neveu, criptóloga que trabalhava para a polícia francesa. Acreditando que o professor de simbologia Robert Langdon não era o culpado pelo crime, conforme tinha sido acusado pela polícia, Sophie resolveu ajudá-lo a fugir e a encontrar o verdadeiro assassino. Aliando os conhecimentos do simbologista Robert Langdon aos segredos de família que Sophie detinha, o casal conseguiu chegar à resolução do crime, mesmo fugindo da polícia enquanto realizava as buscas - algo que também não acontecia com o detetive clássico, que jamais seria acusado de ser o culpado pelos crimes. A polícia, por sua vez, absolveu Robert Langdon da acusação quando encontrou a verdadeira identidade do assassino. Robert Langdon e Sophie Neveu, portanto, realizaram performances eficazes nessa narrativa, mesmo sem 
ter experiência em investigações criminais. Eles usaram seus conhecimentos sobre o misticismo ao redor do crime para estabelecer um plano de ação preciso no qual deveriam descobrir o segredo protegido por Jacques Saunière e impedir o criminoso de revelá-lo.

Por terem realizado a investigação com tanta proximidade e cumplicidade, Robert Langdon e Sophie Neveu acabaram se envolvendo amorosamente. Segundo uma das regras de Van Dine para a boa escritura da narrativa policial (apud MASSI, 2010, p. 34), a intriga amorosa não deve fazer parte desse tipo de texto a fim de não perturbar a investigação puramente racional em busca dos criminosos. No entanto, há um companheirismo muito forte estabelecido entre o casal que os auxilia no compartilhamento das informações e na concretização da investigação. Sophie sentia muita gratidão por Langdon tê-la ajudado a conhecer sua verdadeira história. 0 simbologista, por sua vez, devia sua liberdade à Sophie, que o livrou da acusação pela morte de Jacques Saunière.

Em Os crimes do mosaico, o personagem que realizou a investigação em busca da identidade do criminoso foi Dante Alighieri, o poeta e prior da cidade de Florença. Muito orgulhoso, ele não aceitava ajuda nem opinião de qualquer outra pessoa e se dizia capaz de encontrar o criminoso sozinho - esse é o único romance policial místico-religioso em que a investigação é realizada por apenas um sujeito. De fato, Dante Alighieri conseguiu cumprir seu papel e encontrar o assassino Veniero Marin e sua cúmplice, Antília. 0 casal estava pronto para fugir da cidade quando foi descoberto e pediu a Dante que permitisse sua fuga dentro de uma hora. Em troca, daria a ele os mapas roubados, que levavam à descoberta de um novo continente repleto de ouro. Esses mapas continham as rotas dos ventos, sem as quais seria impossível chegar à nova terra. Dante aceitou a proposta, 
mas não contou a verdade a ninguém, disse apenas que os misteriosos criminosos haviam fugido.

Nesse romance policial místico-religioso, além de omitir a verdade da sociedade de Florença, que confiava nele e aguardava o resultado da investigação, Dante Alighieri não puniu o criminoso, pois preferiu satisfazer desejos individuais, assim como o assassino havia feito. Por outro lado, a fuga de Veniero da cidade garantiria que outros assassinatos não ocorressem, tarefa que também seria destinada ao detetive do gênero policial. Sendo assim, os leitores dessa narrativa e o destinador-manipulador de Dante não podem considerar sua performance eficaz, pois ele não cumpriu o contrato fiduciário estabelecido com a sociedade, já que era o prior de Florença. Ao contrário da programação estabelecida, o prior protegeu a identidade do assassino e não lhe aplicou qualquer forma de punição. Assim, sua ação não pode ser considerada eficaz, pois ele mudou de plano após ser tentado pelo criminoso.

Em $O$ último templário, a investigação foi feita por uma arqueóloga, Tess Chaykin, que presenciou um dos crimes realizados pelo assassino, o ataque à exposição "Relíquias do Vaticano" no Museu Metropolitano de Arte. Ao contrário da polícia, que buscava a identidade do sujeito que depredou a exposição e assassinou os seguranças, Tess Chaykin desejava recuperar os objetos roubados do Museu e entender a importância que eles tinham para os ladrões. Tess Chaykin sabia que um dos objetos serviria para ler mapas antigos e poderia indicar o local onde estava guardado um tesouro templário. O policial Sean Reilly ficou encarregado de deter Tess para que ela não atrapalhasse a investigação da polícia. Entretanto, acabou apaixonando-se por ela e ajudando-a na tentativa de recuperar os objetos roubados. Embora nesse romance policial místico-religioso, como em $O$ código Da Vinci, também 
haja uma relação amorosa entre a arqueóloga Tess Chaykin e o policial Sean Reilly, o que era inadmissível ao gênero policial (como já explicado anteriormente), esse envolvimento acabou servindo para que o policial protegesse a vida de Tess, permitindo que ela prosseguisse nas buscas.

Entretanto, Tess Chaykin não realizou uma performance eficaz, pois acabou sendo ameaçada de morte pelo assassino, por ter atrapalhado os planos dele. Ao mesmo tempo, Tess prejudicou a ação da polícia, que além de ter o dever de encontrar o responsável pelo ataque, passou a ter a obrigação de protegê-la por conta de seu envolvimento com Sean Reilly. A primeira causa para o fracasso da investigação de Tess foi a falta de planejamento; ela conduziu suas ações de forma aleatória, seguindo decisões tomadas de imediato, o que a impediu de determinar as regras operatórias de sua performance. Embora tenha encontrado a identidade do criminoso, não se pode dizer que isso seja resultante de sua ação, mas sim do acaso. Além disso, mesmo descobrindo a existência do tesouro templário enterrado havia anos, Tess Chaykin não conseguiu acessá-lo e ler o códex, deixando de cumprir mais uma das missões impostas pela investigação.

Em Anjos e demônios, Robert Langdon e Vittoria Vetra realizaram a investigação em busca do assassino do cientista Leonardo Vetra, pai de Vittoria. 0 diretor do Centro de Pesquisa (CERN) onde a vítima trabalhava, Maximiliam Kohler, fez uma investigação paralela à de Robert e Vittoria vasculhando o diário de trabalho do cientista. Ao descobrir que o Papa e o camerlengo Carlo Ventresca haviam visitado o escritório de Leonardo e analisar os dados sobre o assassinato de Leonardo Vetra, o diretor concluiu que o camerlengo era o assassino. Para comprovar sua descoberta, Maximiliam foi visitar o cardeal e contou a ele tudo o que sabia. Como já pla- 
nejava a morte do diretor, o camerlengo confessou seus crimes. Entretanto, Maximiliam gravou a conversa em uma fita, desempenhando um papel fundamental para a investigação, e a entregou a Robert Langdon antes de ser assassinado pelos guardas do Vaticano, que seguiram as ordens do camerlengo. Com essa gravação, Robert Langdon conseguiu provar que o jovem era o culpado.

Nessa narrativa, o papel de Maximiliam não se assemelha ao dos "auxiliares do saber" ou "pseudodetetives" (MARTINS, 2000), já que sua revelação é fruto da investigação que ele vinha realizando sozinho. Se o propósito das buscas realizadas por Vittoria Vetra e Robert Langdon fosse apenas encontrar a identidade do assassino, elas teriam perdido o sentido quando Maximiliam Kohler entregou a confissão do camerlengo a Robert Langdon. No entanto, o casal também queria entender por que o jovem membro da Igreja havia assassinado um cientista e quatro cardeais e o que ele esperava receber em troca.

Nota-se que, nesse romance policial, há duas investigações realizadas por sujeitos diferentes: Maximiliam Kohler quer encontrar o assassino, enquanto Robert Langdon e Vittoria Vetra querem entender os motivos para a morte de Leonardo Vetra e as implicações que o roubo de seu laboratório traria para a sociedade. A ação de Maximiliam Kohler foi eficaz, pois foi realizada a partir de uma programação, de um plano de ação traçado de forma objetiva e precisa. Tanto é que, mesmo tendo sido assassinado pelo criminoso, Maximiliam conseguiu revelar sua identidade. Não se pode dizer o mesmo a respeito da ação de Robert Langdon e Vittoria Vetra, pois eles não estavam seguindo regras operatórias ao realizarem suas ações - assim como Tess Chaykin, de $O$ último templário. Além de não terem conseguido encontrar a identidade 
do assassino, o casal só pôde entender as causas e as consequências do crime após a revelação feita por Maximiliam Kohler, o que demonstra a falta de eficiência em suas ações. Nesse romance policial místico-religioso, também há uma relação amorosa entre Robert Langdon e Vittoria Vetra, que só se concretiza após o fim da investigação e, portanto, não atrapalha o andamento das buscas.

No romance policial místico-religioso $O$ símbolo perdido, o sequestrador de Peter Solomon manteve a vítima em cativeiro e fez contato com o professor universitário de simbologia Robert Langdon. Langdon era amigo de Peter Solomon havia vários anos e foi convocado a auxiliar o sequestrador na decifração de uma pirâmide maçônica em troca da vida de Peter. A polícia, por sua vez, estava perseguindo o criminoso a fim de impedir a revelação, na internet, de um vídeo contendo vários rituais maçônicos, nos quais apareciam membros do governo e autoridades locais que escondiam sua pertença à fraternidade maçônica.

Assim como Tess Chaykin, de $O$ último templário, Robert Langdon atrapalhou a investigação da CIA em alguns momentos por acreditar que poderia encontrar o assassino sozinho e pela ânsia de salvar a vida de seu amigo, Peter Solomon, que corria perigo nas mãos do sequestrador. Por outro lado, ele conhecia muito bem os símbolos da maçonaria - ao contrário da policial encarregada da investigação - e auxiliou a polícia na decifração dos códigos. Além disso, o assassino queria matar Robert Langdon após decifrar a pirâmide, mas acabou fazendo com que a polícia o protegesse. Ao contrário do que ocorreu nos outros romances policiais de cunho místico-religioso, em que o criminoso buscava impedir que alguém revelasse o segredo protegido pela Igreja à sociedade, em $O$ símbolo perdido foi a CIA quem protegeu os segredos da maçonaria, pois 
muitos membros da polícia eram maçons e haviam realizado os rituais gravados pelo sequestrador no vídeo.

Nessa narrativa também há duas investigações: uma realizada pela CIA e outra por Robert Langdon, com auxílio de Katherine Solomon, irmã da vítima. A ação da polícia foi planejada desde o início, em virtude da experiência do grupo em investigações criminosas, e não deixou de ser eficaz apesar das adversidades provocadas pelo criminoso. Já a ação de Robert Langdon, ao contrário, não tinha planejamento pelo fato de ele ter sido surpreendido pelo assassino - ao chegar ao Capitólio para proferir uma palestra e encontrar o braço de seu amigo no chão da rotunda. Robert Langdon ficou abalado emocionalmente por saber que Peter Solomon estava correndo perigo e, ao mesmo tempo, sentiu-se mal por ter se deixado enganar com tanta facilidade. Consequentemente, a ação de Robert Langdon não foi eficaz.

A partir dessas descrições dos sujeitos que realizam as investigações nos romances policiais místico-religiosos, nota-se a normalidade e a humanização no perfil desses personagens. Ao contrário de Auguste Dupin, Sherlock Holmes, Hercule Poirot, entre outros detetives de romances policiais clássicos, que trabalhavam como profissionais e sempre eram infalíveis, Guilherme de Baskerville, Berequias Zarco, Farid, Dante Alighieri, Tess Chaykin, Robert Langdon, Sophie Neveu, Vittoria Vetra, Maximiliam Kohler e Katherine Solomon são sujeitos normais, que têm ocupações profissionais não relacionadas à investigação e, por isso, nem sempre conseguem desempenhar o papel de detetive, que lhes é atribuído no enredo, de forma eficaz.

Esses sujeitos têm em comum o dever-fazer ou quererfazer a investigação e se tornam "detetives" por diferentes motivos, sejam eles pessoais ou profissionais. Entre os moti- 
vos pessoais encontram-se: comprovar sua competência após ser manipulado por um destinador-manipulador de seu fazer (Guilherme de Baskerville, em $O$ nome da Rosa, e Dante Alighieri, em Os crimes do mosaico), vingar a morte de um ente querido (Berequias Zarco, em $O$ último cabalista de Lisboa), tentar salvar a vida da vítima (Robert Langdon e Katherine Solomon, em $O$ símbolo perdido), fugir de uma acusação policial (Robert Langdon, em $O$ código Da Vinci), possuir um envolvimento afetivo com a vítima (Robert Langdon, em $O$ símbolo perdido). Entre os profissionais, por outro lado, estão: buscar o desenvolvimento da carreira, como a arqueóloga Tess Chaykin de $O$ último templário; e aplicar os conhecimentos necessários para decifrar as pistas deixadas pelo criminoso, como o simbologista Robert Langdon em Anjos e demônios, e evitar novas vítimas. Nesses últimos casos, nota-se que, quando a motivação é profissional, não se relaciona à profissão de detetive, mas sim às atividades realizadas por esse sujeito em seu cotidiano.

Enquanto a motivação do detetive clássico estava sempre ligada à sua profissão, no romance policial místico-religioso a profissão desses sujeitos não é a de detetive e, consequentemente, a motivação para que realizem a investigação é outra. 0 detetive tradicional agia porque tinha a obrigação de realizar a investigação após ter sido manipulado por um sujeito ligado à vítima, na maioria das vezes. No romance policial místico-religioso, porém, é a vontade ou o dever de salvar a vítima que transforma sujeitos normais em "detetives", ou seja, que faz desses sujeitos seus próprios destinadores-manipuladores. 


\section{Considerações finais}

Embora tenhamos tomado muito cuidado para não nomear de "detetives" os sujeitos que realizam a investigação nos romances policiais místico-religiosos, não encontramos uma definição mais adequada para descrevê-los. Evitamos a palavra "detetive", pois ela não foi usada pelos autores que criaram tais personagens. Chamá-los de "investigadores" também não faria sentido, pois nem sempre eles estão encarregados de investigar algo. Uma das causas de tal dificuldade é a heterogeneidade das atividades desenvolvidas por esses sujeitos, sendo que há um professor, uma criptóloga, uma arqueóloga, alguns cientistas, jovens cabalistas, entre outros. A partir disso, podemos concluir que não é a ocupação dos sujeitos que determina seu envolvimento com a investigação, mas sim a relação que possuíam com as vítimas ou com os segredos que elas pretendiam divulgar ou proteger. A estrutura de gênero policial só se manifesta nessas narrativas em função do segredo místico-religioso, portanto, é esse segredo que define o sujeito que vai realizar a investigação no romance policial místico-religioso.

Dessa forma, nota-se uma transformação no perfil dos "detetives" dos romances policiais místico-religiosos em virtude das exigências que o enredo faz a eles: sujeitos normais são modalizados a realizar uma investigação a partir de um crime com o qual podem ter uma relação direta (querer-fazer) ou não (dever-fazer). A falta de programação na ação investigativa resultante, muitas vezes, de uma solicitação inesperada para que realizem a investigação, e a falta do saber-fazer e do poder-fazer para buscar a identidade do criminoso impede que alguns deles sejam eficazes. 


\section{REFERÊNCIAS}

ALBUQUERQUE, P. M. e. Os maiores detetives de todos os tempos: o herói na evolução da estória policial, ensaio. Rio de Janeiro: Civilização Brasileira; Brasília: Instituto Nacional do Livro, 1973.

BROWN, D. 0 símbolo perdido. Tradução de Fernanda Abreu. Rio de Janeiro: Sextante, 2009.

. O código Da Vinci. Tradução de Celina Cavalcante Falck-Cook. Rio de Janeiro: Sextante, 2004a.

Anjos e demônios. Tradução de Maria Luiza Newlands da Silveira. Rio de Janeiro: Sextante, 2004b.

ECO, U. O nome da Rosa. Tradução de Aurora Fornoni Bernardini e Homero Freitas de Andrade. 2. ed. Rio de Janeiro: Nova Fronteira, 2010.

GREIMAS, A. J. Du Sens II. Essais sémiotiques. Paris: Éditions du Seuil, 1983.

GREIMAS, A. J.; COURTÉS, J. Dicionário de Semiótica. São Paulo: Contexto, 2008.

KHOURY, R. 0 último templário. Tradução de Vera de Paula Assis. Rio de Janeiro: Ediouro Publicações, 2006.

LEONI, G. Os crimes do mosaico. Tradução de Gian Bruno Grosso. São Paulo: Planeta do Brasil, 2006.

MARTINS, M. M. Constituintes do gênero policial: natureza, percursos e métodos de investigação. In: LOPES, I. C.; HERNANDES, N. (Org.). Semiótica: objetos e práticas. São Paulo: Contexto, 2005. p. 169-190.

Narrativa policial: uma abordagem semiótica. 2000. 
284f. Dissertação (Mestrado em Semiótica e Linguística Geral) - Faculdade de Filosofia, Letras e Ciências Humanas, Universidade de São Paulo, São Paulo, 2000.

MASSI, F. Os romances policiais místico-religiosos mais vendidos no Brasil de 1980 a 2009: questões de narratividade e de actorialização. 2013. 171f. Tese (Doutorado em Linguística e Língua Portuguesa) - Faculdade de Ciências e Letras de Araraquara, Universidade Estadual Paulista, Araraquara, 2013.

A configuração dos romances policiais mais vendidos no Brasil de 2000 a 2009: canônica ou inovadora? 2010. 144f. Dissertação (Mestrado em Linguística e Língua Portuguesa) - Faculdade de Ciências e Letras de Araraquara, Universidade Estadual Paulista, Araraquara, 2010.

POE, E. A. Antologia de contos extraordinários. Tradução de Brenno Silveira. Rio de Janeiro: BestBolso, 2010.

ZIMLER, R. 0 último cabalista de Lisboa. Tradução de Fernando Klabin. Rio de Janeiro: Relume Dumará, 2007.

Artigo recebido em setembro de 2014 e aprovado em dezembro de 2014.

Disponível em: http://seer.fclar.unesp.br/casa 